\title{
Numerical Analysis of the Influence of Seepage on the Displacement Law of Different Overburden Strata
}

\author{
WANG Yun-ping ${ }^{1,}$, ZHAO De-shen ${ }^{2, b^{*}}$ \\ ( 1.Key Laboratory of Liaoning Province for Prediction \& Control on Complicated Structure System, \\ Dalian University, Dalian 116622, China ) \\ a zhaodeshen@dlu.edu.cn , bWangYunPingJG211@163.com
}

\begin{abstract}
Keywords: different overburden structure; sedimentation value; displacement field; horizontal deformation; simulate; mining

Abstract. The combination of different rock properties will make different effects of the Deformation and Failure in Overlying strata, this paper uses the ADINA finite element software to establish two-dimensional model to simulate analysis the four kinds of different overburden structures displacement field variation characteristics in the conditions of seepage and mining. The results show that when mining is completed, the surface of overlying strata structure were formed a completely symmetrical subsidence basin and antisymmetric horizontal movement curve, The sinking value of open-off cut and the working face is above the inflection point is half of the maximum subsidence, the curve slope from the boundary to the inflection point increases gradually, the curve slope from the inflection point to the center point becomes smaller. The maximum displacements due to overlying lithology vary, the surface maximum settlement value is $3.80 \mathrm{M}$ and the minimum settlement value is $2.34 \mathrm{~m}$. The floor heave has little difference, the maximum value and the minimum value is only $0.17 \mathrm{~mm}$.
\end{abstract}

\section{Introduction}

With the pace of development of China, the demand for coal is increasing. However, the frequent occurrence of water flooding and collapse accidents in mining has reduced the production efficiency and endangered the life [1-4]. In this paper, using the finite element software ADINA to simulate the process of mining, based on the engineering geological data of a coal mine working surface and obtain the displacement field variation law of overlying strata in the process of mining. Finally, by changing the lithology of overlying strata (hard-hard type, soft-hard type, hard-soft type and alternating hard and soft type) to study the influence of seepage on the displacement law of different overburden strata.

\section{General situation of overlying strata}

The shape and height of the fractured zone is controlled by the lithology of the overlying strata that is the main factor. Because of the sedimentary conditions of coal bed, the long geological deposit and the movement of geological structure, the overlying strata of the coal bed is composed of many kinds of rock, and the typical structure of overlying strata: hard-hard type, soft-hard type, hard-soft type, alternating hard and soft type. In order to reduce the influence of mining depth, mining thickness, coal seam dip and other factors on the mechanical model of different overburden. The above conditions are as follows: the depth of mining $\mathrm{H}=733 \mathrm{~m}$, coal seam thickness $\mathrm{M}=9 \mathrm{~m}$, inclined length $\mathrm{L}=120 \mathrm{~m}$, the length $\mathrm{D}=1200 \mathrm{~m}$, the depth of water is $5.58 \mathrm{~m}$.

\section{Mechanical parameters of overlying rock}

According to the rock mechanics parameters manual selecting the physical mechanics and hydraulic parameters of different coal rocks are listed in table 1- 4. The bulk modulus of the fluid is 2.3GPa, and the fluid density is $1000 \mathrm{~kg} / \mathrm{m} 3$. 
Tab.1 Mechanical parameters of hard-hard type

\begin{tabular}{cccccccc}
\hline rock stratum & $\begin{array}{c}E \\
(\mathrm{GPa})\end{array}$ & $v$ & $\begin{array}{c}P \\
\left(\mathrm{~g} / \mathrm{cm}^{3}\right)\end{array}$ & $\begin{array}{c}C \\
(\mathrm{MPa})\end{array}$ & $\begin{array}{c}\Phi \\
\left({ }^{\circ}\right)\end{array}$ & $\begin{array}{c}\sigma_{\mathrm{c}} \\
(\mathrm{MPa})\end{array}$ & $\begin{array}{c}\sigma_{\mathrm{t}} \\
(\mathrm{MPa})\end{array}$ \\
\hline The Quaternary & 0.825 & 0.36 & 2.09 & 0.6 & 31.7 & 4.5 & 0.60 \\
Sandstone & 5.63 & 0.27 & 2.29 & 3.9 & 38 & 33 & 1.12 \\
Powder sandstone & 5.63 & 0.27 & 2.29 & 3.9 & 37 & 45 & 1.12 \\
Sandy shale & 8.43 & 0.34 & 2.49 & 15.8 & 32 & 1.31 \\
Conglomerate & 11.68 & 0.33 & 2.16 & 2.3 & 41.8 & 75 & 1.69 \\
Coal seam & 1.1 & 0.29 & 1.30 & 0.2 & 39.8 & 2.5 & 0.22 \\
conglomerat & 11.94 & 0.33 & 2.39 & 7.6 & 42.4 & 73 & 1.57 \\
\hline
\end{tabular}

Tab.2 Mechanical parameters of soft-hard type

\begin{tabular}{cccccccc}
\hline rock stratum & $\begin{array}{c}E \\
(\mathrm{GPa})\end{array}$ & $v$ & $\begin{array}{c}P \\
\left(\mathrm{~g} / \mathrm{cm}^{3}\right)\end{array}$ & $\begin{array}{c}C \\
(\mathrm{MPa})\end{array}$ & $\begin{array}{c}\Phi \\
\left({ }^{\circ}\right)\end{array}$ & $\begin{array}{c}\sigma_{\mathrm{c}} \\
(\mathrm{MPa})\end{array}$ & $\begin{array}{c}\sigma_{\mathrm{t}} \\
(\mathrm{MPa})\end{array}$ \\
\hline The Quaternary & 0.825 & 0.36 & 2.09 & 0.6 & 31.7 & 4.5 & 0.60 \\
Sandy shale & 8.43 & 0.34 & 2.29 & 6.32 & 37 & 65 & 1.36 \\
Sandstone & 2.7 & 0.33 & 2.458 & 1.65 & 38 & 17 & 1.65 \\
Mudstone & 2.45 & 0.33 & 2.27 & 1.65 & 38 & 17.2 & 0.62 \\
Sand shale & 2.7 & 0.33 & 2.47 & 1.5 & 38 & 18 & 1.02 \\
Oil shale & 2.25 & 0.33 & 2.16 & 0.23 & 41.8 & 19.7 & 0.87 \\
Coal seam & 1.1 & 0.29 & 1.30 & 0.2 & 39.8 & 2.5 & 0.22 \\
conglomerate & 11.94 & 0.33 & 2.39 & 7.6 & 42.4 & 73 & 1.57 \\
\hline
\end{tabular}

Tab.3 Mechanical parameters of hard-soft type

\begin{tabular}{|c|c|c|c|c|c|c|c|}
\hline rock stratum & $\begin{array}{c}E \\
(\mathrm{GPa})\end{array}$ & $v$ & $\begin{array}{c}P \\
\left(\mathrm{~g} / \mathrm{cm}^{3}\right)\end{array}$ & $\begin{array}{c}C \\
(\mathrm{MPa})\end{array}$ & $\begin{array}{c}\Phi \\
\left(^{\circ}\right)\end{array}$ & $\begin{array}{c}\sigma_{\mathrm{c}} \\
(\mathrm{MPa})\end{array}$ & $\begin{array}{c}\sigma_{\mathrm{t}} \\
(\mathrm{MPa})\end{array}$ \\
\hline The Quaternary & 0.825 & 0.36 & 2.09 & 0.6 & 31.7 & 4.5 & 0.60 \\
\hline Sandstone & 3.0 & 0.28 & 2.221 & 3.9 & 46 & 18 & 0.89 \\
\hline Mudstone & 2.55 & 0.33 & 2.227 & 0.9 & 38 & 17.6 & 0.62 \\
\hline Sand shale & 2.55 & 0.25 & 2.247 & 4.4 & 39 & 19 & 1.02 \\
\hline Powder sandstone & 5.63 & 0.27 & 2.29 & 3.9 & 38 & 43 & 1.12 \\
\hline Sandy shale & 8.43 & 0.34 & 2.30 & 6.32 & 37 & 60 & 1.92 \\
\hline Coal seam & 1.1 & 0.29 & 1.30 & 0.2 & 39.8 & 2.5 & 0.22 \\
\hline conglomerate & 11.94 & 0.33 & 2.39 & 7.6 & 42.4 & 73 & 1.57 \\
\hline
\end{tabular}

Tab.4 Mechanical parameters of alternating hard and soft type

\begin{tabular}{cccccccc}
\hline rock stratum & $\begin{array}{c}E \\
(\mathrm{GPa})\end{array}$ & $v$ & $\begin{array}{c}P \\
\left(\mathrm{~g} / \mathrm{cm}^{3}\right)\end{array}$ & $\begin{array}{c}C \\
(\mathrm{MPa})\end{array}$ & $\begin{array}{c}\Phi \\
\left({ }^{\circ}\right)\end{array}$ & $\begin{array}{c}\sigma_{\mathrm{c}} \\
(\mathrm{MPa})\end{array}$ & $\begin{array}{c}\sigma_{\mathrm{t}} \\
(\mathrm{MPa})\end{array}$ \\
\hline The Quaternary & 0.825 & 0.36 & 2.09 & 0.6 & 31.7 & 4.5 & 0.60 \\
Sandstone & 2.55 & 0.25 & 2.247 & 1.76 & 39 & 17.6 & 1.02 \\
Sand shale & 2.7 & 0.33 & 2.440 & 1.65 & 38 & 17 & 1.16 \\
Big rocks & 8.13 & 0.34 & 2.29 & 3.75 & 37 & 60 & 1.33 \\
Sandy shale & 8.43 & 0.34 & 2.29 & 6.32 & 37 & 70 & 1.31 \\
Coal seam & 1.1 & 0.29 & 1.30 & 0.2 & 39.8 & 2.5 & 0.22 \\
conglomerate & 11.94 & 0.33 & 2.39 & 7.6 & 42.4 & 73 & 1.57 \\
\hline
\end{tabular}

\section{Establishment of numerical model}

The numerical model of different overburden structure is as follows: $Y \times Z=1355 \mathrm{~m} \times 802 \mathrm{~m}$, $\mathrm{Y}$ is the trend and $\mathrm{Z}$ is the direction of depth. Every time the advance of mining is $15 \mathrm{~m}$, the total length is 795m. The modle contains 5994 units, 6234 nodes. Figure 1 is schematic diagram of the model. 


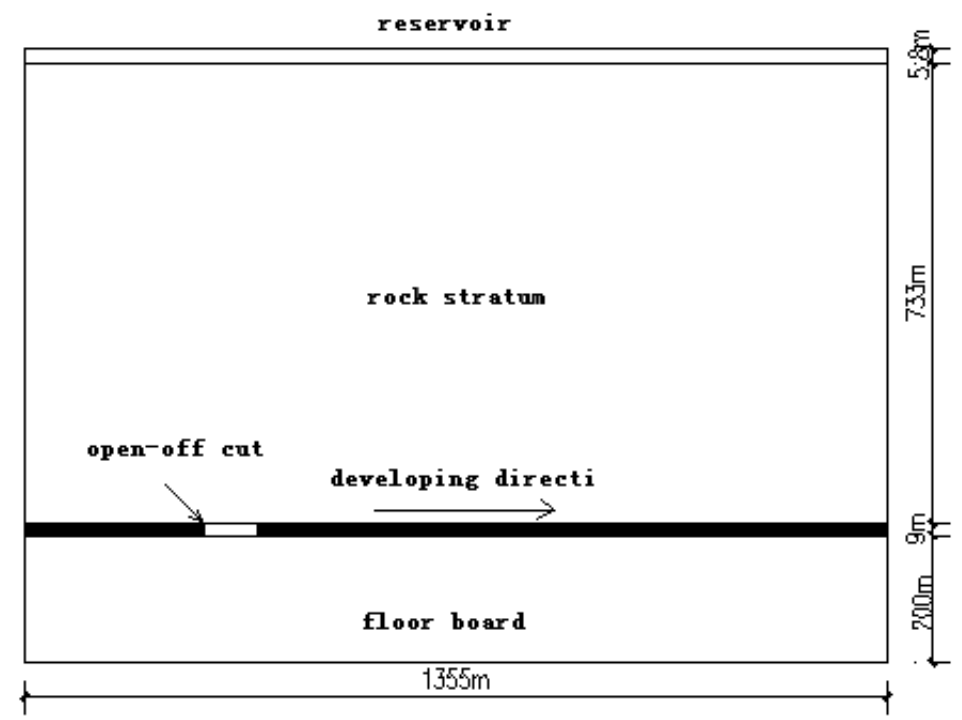

Fig. 1 Sketch map of coal mine working surface

\section{Numerical simulation analysis of displacement field}

\subsection{Analysis of vertical displacement field}

Coal seam excavation caused the stress redistribution of overburden, in the process of stress equilibrium will occur the rock mass subsidence above the area of goaf and coal seam floor heave and so on, but the size of the strata movement can be different because of the different type of overlying strata. Fig.2 3 represents the distribution of the vertical displacement field of the different overburden models when working with the $135 \mathrm{~m}$ and $405 \mathrm{~m}$. It can be seen from the diagram that Because of the different overlying strata the subsidence of the roof is different, in general, the subsidence of the composite is larger than that of the uniform lithology and the amount of the floor of coal seam is basically the same.

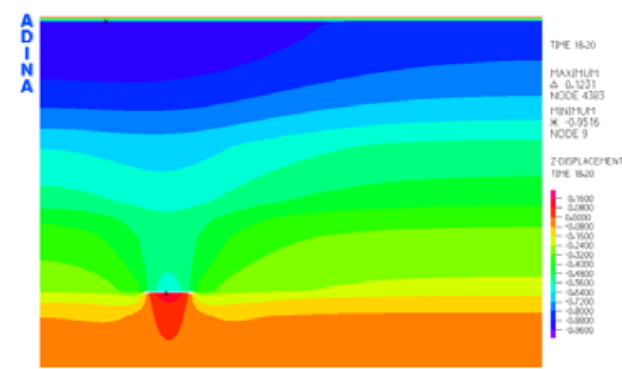

a. hard-hard type

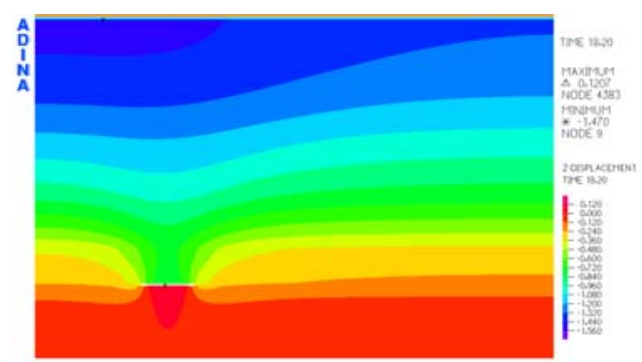

b. hard-soft type

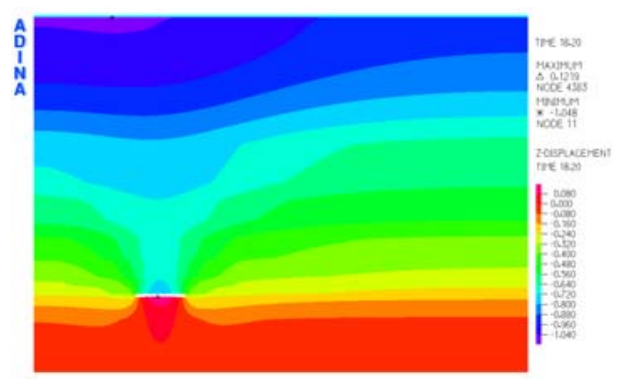

b. soft-hard type

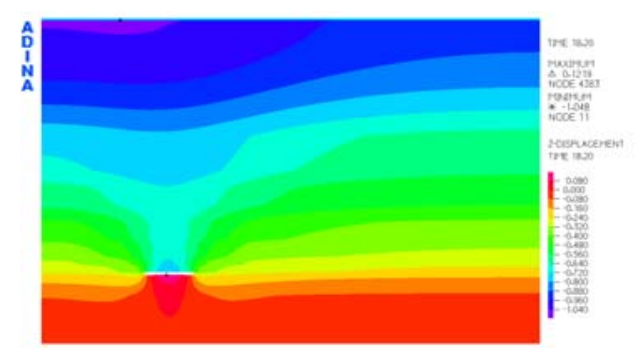

d.alternating hard and soft type

Fig. 2 Vertical displacement field distribution of different overburden models promoting $135 \mathrm{~m}$ along strike of working face

Figure 2 shows the distribution of the vertical displacement field when the excavation face is pushed forward by $135 \mathrm{~m}$ it can be seen that the mining disturbance caused obvious subsidence of overlying strata has begun to spread to the surface, forming the sinking basin. Because of the different 
overlying strata the subsidence amount of the roof is different [5], which from big to small are soft-hard type is $0.96 \mathrm{~m}$, hard-soft type is $0.84 \mathrm{~m}$, alternating hard and soft type is $0.72 \mathrm{~m}$, hard-hard type is $0.64 \mathrm{~m}$. The bottom heaves of the different overlying strata are both for $12 \mathrm{~cm}$.

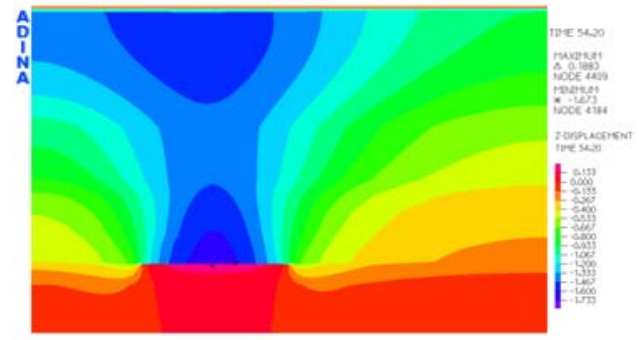

a. hard-hard type

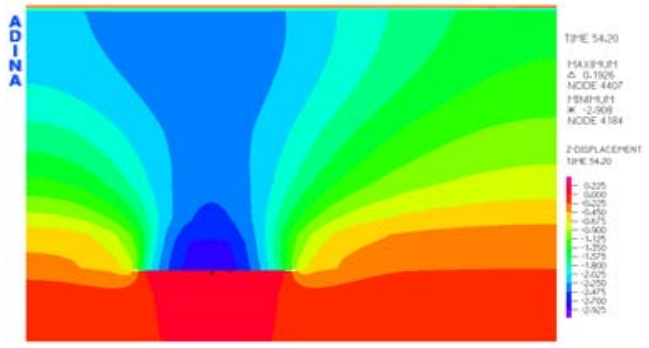

b. hard-soft type

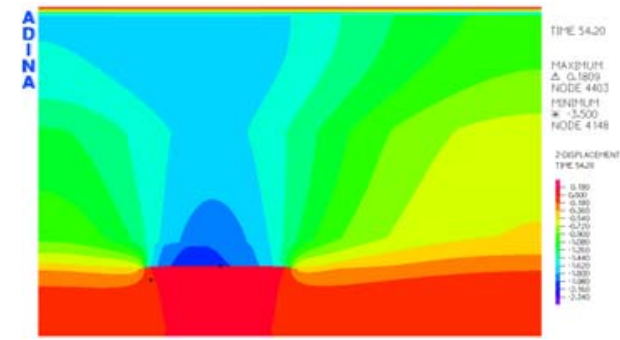

b. soft-hard type

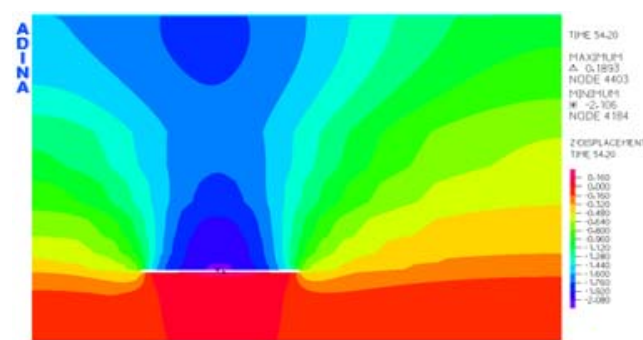

d.alternating hard and soft type

Fig. 3 Vertical displacement field distribution of different overburden models promoting $405 \mathrm{~m}$ along strike of working face

Figure 3 shows the distribution of the vertical displacement field when promoting 405m along strike of working face it can be seen that with the development of the coal seam, the influence of the mining disturbance is increased, the total subsidence of the overlying strata is increasing rapidly and the vault of annular displacement nephogram has been developed to the surface, which causes the whole deformation of the soil. The subsidence amount of the roof of different overlying strata from big to small are: soft-hard type is $3.5 \mathrm{~m}$, hard-soft type is $2.9 \mathrm{~m}$, alternating hard and soft type is $2.1 \mathrm{~m}$, hard-hard type is $1.67 \mathrm{~m}$. The bottom heaves of the different overlying strata are little differences, the maximum is $19.26 \mathrm{~mm}$ and the minimum is $18.09 \mathrm{~mm}$, the maximum and minimum values of the bottom drum are only a difference of $0.17 \mathrm{~mm}$.

\subsection{Surface deformation analysis}

Figure 4 shows the surface subsidence of different rock structures in the completion of the mining, namely coal seam to promote $795 \mathrm{~m}$.It can be seen that when mining is completed, the surface of overlying strata structure were formed a completely symmetrical subsidence basin and ant symmetric horizontal movement curve, The sinking value of open-off cut and the working face is above the inflection point is half of the maximum subsidence, the curve slope from the boundary to the inflection point increases gradually, the curve slope from the inflection point to the center point becomes smaller. The maximum sedimentation value is different because of the difference of overlying strata, the sinking amounts from big to small are: soft-hard type is $3.80 \mathrm{~m}$, hard-soft type is $3.29 \mathrm{~m}$, alternating hard and soft type is $2.85 \mathrm{~m}$, hard-hard type is $2.34 \mathrm{~m}$. It can be seen that, when the other conditions are the same, the structure of hard-hard type is the most favorable to the stability of the surface. 


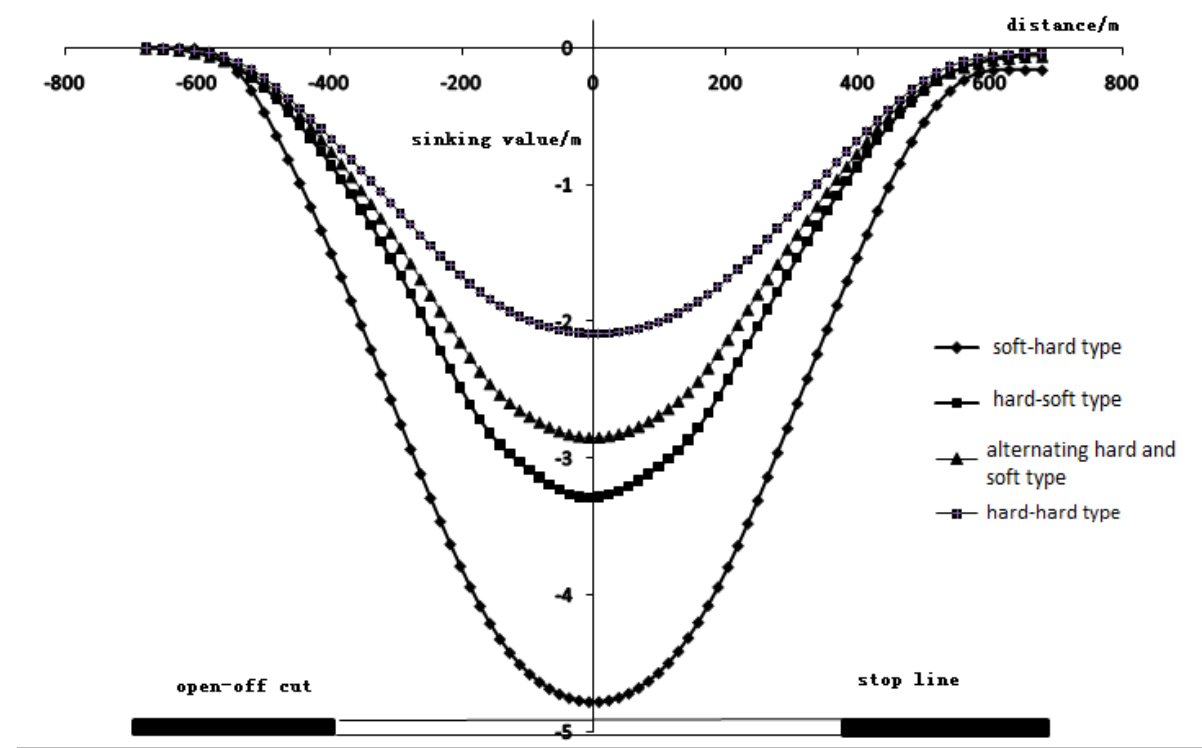

Fig. 4 Ground settling curve of different overburden models when mining is completed

\section{Summary}

1) Because of the different overlying strata the subsidence amount of the roof is different, when the other conditions are the same, the roof subsidence from big to small are soft-hard type, hard-soft type, alternating hard and soft type and hard-hard type.

2) When the mining is finished, the surface of overlying strata structure were formed a completely symmetrical subsidence basin and ant symmetric horizontal movement curve, The sinking value of open-off cut and the working face is above the inflection point is half of the maximum subsidence, the curve slope from the boundary to the inflection point increases gradually, the curve slope from the inflection point to the center point becomes smaller. The sinking amounts from big to small are: soft-hard type is $3.80 \mathrm{~m}$, hard-soft type is $3.29 \mathrm{~m}$, alternating hard and soft type is $2.85 \mathrm{~m}$, hard-hard type is $2.34 \mathrm{~m}$.

\section{Acknowledgements}

The author would like to thank the financial support by the National Natural Science Foundation of China (Grant No. 51274051). ZHAO Deshen(1957-) male,the elm city of Jilin Province,university professor, Doctor. E-mail: zhaodeshen@dlu.edu.cn.

\section{References}

[1] $\mathrm{Wu}$ Jinmei. Analysis of the trend of large and medium cities coal circulation [D]. Chinese Academy of Social Sciences of graduate school, 2000.

[2] Qiu Feng, Zhu Xun. China coal industry safety problems and Countermeasures of [J]. supervision of contemporary economic management, 2007,04:57-60.

[3] Peng Linjun, Zhao Xiaodong, Song Zhenqi, Li Ligang. Prediction and control technology of roof of coal mine [J]. Journal of Xi'an University of Science And Technology, 2009,02:140-143+153.

[4] Chen Juan, Zhao Yaojiang. Analysis of coal mine accidents in China in recent ten years and Its Revelation [J]. coal engineering, 2012,03:137-139.

[5] Zhang Jinhu, Wu Shiliang, Zhou Mao. The numerical analysis of the overlying strata movement in the short wall of different overburden structures [J]. Journal of Xi'an University of Science And Technology, 2011,03:263-266. 